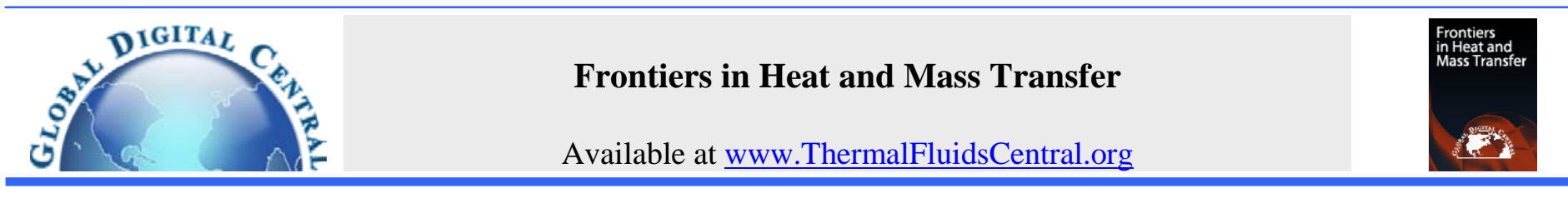

\title{
NUMERICAL SOLUTIONS FOR A NANOFLUID PAST OVER A STRETCHING CIRCULAR CYLINDER WITH NON-UNIFORM HEAT SOURCE
}

\author{
A. Rasekh ${ }^{\mathrm{a}, *}$, D.D. Ganji ${ }^{\mathrm{b}}, \mathrm{S}$. Tavakoli $^{\mathrm{b}}$ \\ ${ }^{a}$ Department of Mechanical Engineering, Shahrood University of Technology, Shahrood, Iran \\ ${ }^{b}$ Department of Mechanical Engineering, Babol Noshirvani University of Technology, Babol, Iran
}

\begin{abstract}
The present paper deals with the analysis of boundary layer flow and heat transfer of a nanofluid over a stretching circular cylinder in the presence of non-uniform heat source/sink. The governing system of partial differential equations is converted to ordinary differential equations by using similarity transformations, which are then solved numerically using the Runge-Kutta-Fehlberg method with shooting technique. The solutions for the temperature and nanoparticle concentration distributions depend on six parameters, Prandtl number $P r$, Lewis number $L e$, the Brownian motion parameter $N b$, the thermophoresis parameter $N t$, and non-uniform heat generation/absorption parameters $A^{*}, B^{*}$. Numerical results are presented both in tabular and graphical forms for $0.7 \leq \operatorname{Pr} \leq 10,1 \leq L e \leq 30,0.1 \leq N b \leq 0.5$, and $0.1 \leq N t \leq 0.5$ illustrating the effects of these parameters on thermal and concentration boundary layers. The results reveal that increasing the value of non-uniform heat generation/absorption parameter leads to deterioration in heat transfer rates at the stretching cylinder wall. However, it is found that increasing the value of non-uniform heat generation/absorption parameters results in enhancement the reduced Sherwood number. Moreover, for fixed $\mathrm{Pr}$ and $\mathrm{Le}$, the reduced Nusselt number decreases but the reduced Sherwood number increases as the Brownian motion and thermophoresis effects become stronger.
\end{abstract}

Keywords: Nanofluid; Non-uniform heat generation/absorption; Stretching cylinder; boundary layer.

\section{INTRODUCTION}

During the last many years, the study of boundary layer flow and heat transfer over a stretching surface has achieved a lot of success because of its large number of applications such as extrusion, wire drawing, metal spinning, hot rolling, etc (Altan and Gegel, 1979; Tidmore and Klein, 1970). After the pioneering work by Sakiadis (1971), a large amount of literature is available on boundary layer flow both of Newtonian and non-Newtonian fluids over linear and nonlinear continuous moving surface (Liu, 2004; Khan et al., 2003; Nadeem et al., 2010; Dandapat et al., 2007; Mahantesh et al., 2011; Pal and Mondal, 2012; Nandeppanavar, 2010). However, only a limited attention has been paid to the study of stretching circular cylinder. Mention may be made to the works of Wang (1988), Chamkha et al. (2010), Ishak et al. (2008) and Joneidi et al. (2010).

More recently, convective heat transfer in nanofluids is a topic of major contemporary interest both in sciences and engineering. The word "nanofluid" coined by Choi (1995) describes a liquid suspension containing ultra-fine particles (diameter less than $50 \mathrm{~nm}$ ). The theory of nanofluids has presented several fundamental properties with the large enhancement in thermal conductivity as compared to the base fluid (Fan and Wang, 2011). In fact, nanotechnology aims to manipulate the structure of the matter at the molecular level with the goal for innovation in virtually every industry and public endeavor including biological sciences, physical sciences, electronics cooling, transportation, the environment and national security. The literature on nanofluids has been reviewed by Trisaksri and Wongwises (2007),
Wang and Mujumdar (2004), Eastman et al. (2006), and, among several others. Buongiorno (2006) and Kakac and Pramuanjaroenkij (2009) have investigated a comprehensive survey of convective transporting nanofluids. Khan and Pop (2010) studied the boundary layer flow of a nanofluid past a stretching sheet with a constant surface temperature. Following this work, Makinde and Aziz (2011) generalized their analysis to a convective boundary condition instead of an isothermal condition. Hassani et al. (2011) investigated the boundary layer flow of a nanofluid past a stretching sheet. Their solution depended on a Prandtl number Pr, a Lewis number Le, a Brownian motion number $\mathrm{Nb}$ and a thermophoresis is number Nt. The dependency of the local Nusselt and local Sherwood numbers on these four parameters was analytically investigated. They concluded that the reduced Nusselt number decreases with the increase in Prandtl number. Nadeem and Lee (2012) presented the HAM solution for the steady boundary layer flow of nanofluid over an exponentially stretching surface. They showed that boundary layer thickness reduces with the increase in Lewis number. Gorla et al. (2011) have studied the problem of a steady boundary-layer flow of a nanofluid on an isothermal stretching circular cylindrical surface. Kuznetsov and Nield (2010) have examined the influence of nanoparticles on the natural convection boundary layer flow past a vertical plate by using a model in which Brownian motion and thermophoresis are accounted for. They have assumed that both the temperature and the nanoparticle fraction are constant along the wall. Aziz and Khan (2012) investigated the natural convective flow of a nanofluid over a convectively heated vertical plate. They demonstrated that the dimensionless heat flow decreases as both the Brownian motion and thermophoresis parameters increase. Anbuchezhian et al. (2012)

\footnotetext{
${ }^{*}$ Corresponding Author. Email: alireza.rasekh@gmail.com.
} 
studied the problem of laminar fluid flow, which results from the stretching of a vertical surface with variable stream conditions in a nanofluid due to solar energy. They presented that the impact of thermophoresis particle deposition with Brownian motion in the presence of thermal stratification has a substantial effect on the boundary layer flow field, and thus on the heat transfer and nanoparticle volume fraction rate from the sheet to the fluid.

Motivated by the above studies we intend to investigate the steady boundary layer flow of a nanofluid on a circular cylindrical surface with taking into the account of non-uniform heat source/sink. The problem is formulated in such a manner that the partial differential equations governing the flow, temperature and concentration fields are reduced to ordinary differential equations, which are solved numerically using the Runge-Kutta-Fehlberg method with shooting technique. The effects of embedded parameters on fluid velocity, temperature and particle concentration have been shown graphically. The present analysis may be useful as a simple model in understanding more complicated applications to practical problems such as film cooling, polymer fiber coating, and coating of cylindrical wires.

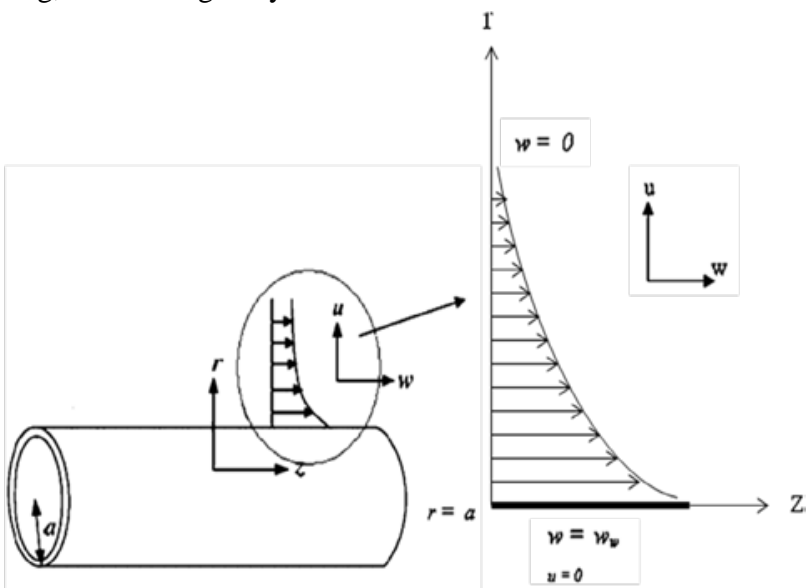

Fig. 1 Geometry of problem under investigation.

\section{PROBLEM FORMULATION}

Consider the steady flow of a nanofluid near the stretching circular cylinder of radius a moving at the linear velocity $\mathrm{w}=2 \mathrm{cz}$, where $\mathrm{c}$ is a constant, as shown in Fig. 1. The physical properties of the fluid are assumed to be constant. Under such condition, the basic steady conservation of mass, momentum, thermal energy and nanoparticles equations for nanofluids can be written as (Buongiorno, 2006),

$$
\begin{aligned}
& \frac{\partial(r w)}{\partial z}+\frac{\partial(r u)}{\partial r}=0, \\
& w \frac{\partial w}{\partial z}+u \frac{\partial w}{\partial r}=v\left(\frac{\partial^{2} w}{\partial r^{2}}+\frac{1}{r} \frac{\partial w}{\partial r}\right) \\
& w \frac{\partial u}{\partial z}+u \frac{\partial u}{\partial r}=-\frac{1}{\rho_{f}} \frac{\partial p}{\partial r}+v\left(\frac{\partial^{2} u}{\partial r^{2}}+\frac{1}{r} \frac{\partial u}{\partial r}-\frac{u}{r^{2}}\right), \\
& w \frac{\partial T}{\partial z}+u \frac{\partial T}{\partial r}=\frac{\alpha}{r} \frac{\partial}{\partial r}\left(r \frac{\partial T}{\partial r}\right)+ \\
& \tau\left\{D_{B}\left(\frac{\partial C}{\partial z} \frac{\partial T}{\partial z}+\frac{\partial C}{\partial r} \frac{\partial T}{\partial r}\right)+\left(\frac{D_{T}}{T_{\infty}}\right)\left[\left(\frac{\partial T}{\partial z}\right)^{2}+\left(\frac{\partial T}{\partial r}\right)^{2}\right]\right\}+\frac{q^{\prime \prime \prime}}{(\rho c)_{f}}, \\
& w \frac{\partial C}{\partial z}+u \frac{\partial C}{\partial r}=\frac{D_{B}}{r} \frac{\partial}{\partial r}\left(r \frac{\partial C}{\partial r}\right)+\left(\frac{D_{T}}{T_{\infty}}\right) \frac{1}{r} \frac{\partial}{\partial z}\left(r \frac{\partial T}{\partial r}\right),
\end{aligned}
$$

where $\tau=\frac{(\rho c)_{p}}{(\rho c)_{f}}$ is the ratio of the nanoparticle heat capacity and the base fluid heat capacity, $q^{\prime \prime \prime}$ is the space and temperature dependent internal heat generation/absorption (non-uniform heat source/sink) which can be expressed in simplest form as (Prasad et al., 2000),

$$
q^{\prime \prime \prime}=\left(\frac{k U_{w}(z)}{2 z v}\right)\left[A^{*}\left(T_{w}-T_{\infty}\right) f^{\prime}(\eta)+B^{*}\left(T-T_{\infty}\right)\right]
$$

where $A^{*}$ and $B^{*}$ are parameters of the space and temperature dependent internal heat generation/absorption. The case $A^{*}>0$ and $B^{*}$ $>0$ corresponds to internal heat generation while $A^{*}<0$ and $B^{*}<0$ correspond to internal absorption.

The boundary conditions for this problem can be written as

$r=a: T=T_{w}, w=U_{w}(z)=2 c z, C=C_{w}$,

$r \rightarrow \infty: T=T_{\infty}, w=0, C=C_{\infty}$,

Introducing the similarity transformation:

$\eta=\left(\frac{r}{a}\right)^{2}, u=-c a\left(\frac{f(\eta)}{\sqrt{\eta}}\right), w=2 c z f^{\prime}(\eta), \theta(\eta)=\frac{T-T_{\infty}}{T_{w}-T_{\infty}}, \phi=\frac{C-C_{\infty}}{C_{w}-C_{\infty}}$

After transformation we have:

$$
\begin{aligned}
& \eta f^{\prime \prime \prime}+f^{\prime \prime}+\operatorname{Re}_{a}\left(f f^{\prime \prime}-f^{\prime 2}\right)=0, \\
& \theta^{\prime \prime}+\frac{\theta^{\prime}}{\eta}+\operatorname{Pr} \theta^{\prime}\left(N_{b} \phi^{\prime}+N_{t} \theta^{\prime}\right)+\frac{\operatorname{Pr}_{a} \operatorname{Re}_{a}}{2 \eta} f \theta^{\prime}+A^{*} f^{\prime}+B^{*} \theta=0, \\
& \phi^{\prime \prime}+\phi^{\prime}\left(\frac{1}{2} \operatorname{Le} \operatorname{Re}_{a} f+\frac{1}{\eta}\right)+\frac{N_{t}}{N_{b}} \frac{1}{\eta} \theta^{\prime}+\frac{N_{t}}{N_{b}} \theta^{\prime \prime}=0,
\end{aligned}
$$

The associated boundary conditions are

$\eta=1: f=0, f^{\prime}=1, \theta=1, \phi=1$,

$\eta \rightarrow \infty: f^{\prime}=0, \theta=0, \phi=0$,

In the previous equations, the primes denote differentiation with respect to $\eta$ and the six parameters are defined by,

$$
\begin{aligned}
& N_{t}=\frac{\varepsilon(\rho c)_{p} D_{T}\left(T_{w}-T_{\infty}\right)}{(\rho c)_{f} T_{\infty} \alpha_{m}}, N_{b}=\frac{\varepsilon(\rho c)_{p} D_{B}\left(C_{w}-C_{\infty}\right)}{(\rho c)_{f} \alpha_{m}}, \\
& \operatorname{Re}_{\mathrm{a}}=\frac{c a^{2}}{2 v}, \quad \text { Le }=\frac{v}{D_{B}}, \operatorname{Pr}=\frac{v}{\alpha}, \tau=\frac{\varepsilon(\rho c)}{(\rho c)_{f}},
\end{aligned}
$$

where $\mathrm{Pr}, \mathrm{Le}, \mathrm{Nb}$ and $\mathrm{Nt}$ denote the Prandtl number, the Lewis number, the Brownian motion parameter and the thermophoresis parameter, respectively. It should be noted that this boundary layer problem reduces to the classical problem of flow and heat and mass transfer due to a stretching cylinder in a viscous fluid when $\mathrm{Nb}$ and $\mathrm{Nt}$ are zero.

The local Nusselt number $N u_{x}$ and the local Sherwood number $S h_{x}$ can be written as (Gorla, et al., 2011),

$$
\begin{aligned}
& N u_{x}=-\frac{q_{w} x}{k\left(T_{w}-T_{\infty}\right)},=-2 \sqrt{\frac{\operatorname{Re}_{z}}{\operatorname{Re}_{a}}} \theta^{\prime}(1), \\
& S h_{x}=-\frac{q_{m} x}{D_{B}\left(C_{w}-C_{\infty}\right)}=-2 \sqrt{\frac{\operatorname{Re}_{z}}{\operatorname{Re}_{a}}} \phi^{\prime}(1),
\end{aligned}
$$

where $q_{w}$ and $q_{m}$ are wall heat and mass flux rates, respectively.

Table 1 Comparison of results for $-f^{\prime \prime}(1)$ when $N_{t}=N_{b}=0$ and

$$
A^{*}=B^{*}=0
$$

$R e_{a}$ Ishak et al. [13] Wang [11] Gorla et al. [26] Present Results

\begin{tabular}{lllll}
\hline 0.5 & 0.8827 & 0.88220 & 0.88700 & 0.8825 \\
1.0 & 1.1781 & 1.17776 & 1.17923 & 1.17927 \\
2.0 & 1.5941 & 1.59390 & 1.59448 & 1.5962 \\
5.0 & 2.4175 & 2.41745 & 2.41755 & 2.4172 \\
10.0 & 3.3445 & - & 3.34467 & 3.3451 \\
\hline
\end{tabular}




\section{NUMERICAL SOLUTION}

The system of coupled non-linear ordinary differential Eqs. (9)(11), subjected to boundary conditions, Eq. (12) were solved numerically by using the fourth-order Runge-Kutta scheme with a systematic guessing of and by the shooting method until the boundary conditions at infinity and decay exponentially to zero. The computations have been done by Maple. The step size is used while obtaining the numerical solution with $\eta_{\max }$, and the accuracy to the fifth decimal place is sufficient for convergence. The value of $\eta \infty$ is found to each iteration loop by the assignment statement. The maximum value of $\eta=\infty$ is determined when the values of unknown boundary conditions at $\eta=0$ do not change to a successful loop with error less than $10^{-7}$. To check the accuracy of our numerical computations, we compare our results with those of other researchers in Tables 1-2. These results pertain to a circumstance when the Brownian and the thermophoresis effects are absent, that is, the fluid is a regular fluid with no nanoparticles and there is no heat source/sink. For all the Reynolds numbers listed in Table 1, the present results of agree with the results of Wang [11], Ishak et al. [13] and Gorla et al. (2011). A comparison is also made for dimensionless temperature gradient for various values of Prandtl number with those reported by Chamkha et al. (2010), and Gorla et al. (2011). The comparison of our results with literature values indicates excellent agreement and therefore our results are highly accurate.

Table 2 Comparison of results for $-\theta^{\prime}(1)$ when $N_{t}=N_{b}=0, \operatorname{Re}=3$

$$
\text { and } A^{*}=B^{*}=0
$$

\begin{tabular}{lccc}
\hline $\operatorname{Pr}$ & Chamkha et al. [12] & Gorla et al. [26] & Present Results \\
\hline 0.70 & 1.15053 & 1.15053 & 1.15051 \\
2.00 & 2.10655 & 2.10654 & 2.10654 \\
7.00 & 4.23743 & 4.23743 & 4.23645 \\
\hline
\end{tabular}

\section{RESULTS AND DISCUSSION}

Numerical analysis is carried out for with employing the shooting technique with a fourth-order Runge-Kutta scheme. The parameters involved in the study are Prandtl number $(\mathrm{Pr})$, Lewis number $(\mathrm{Le})$, nonuniform heat source/sink parameters $\left(A^{*}, B^{*}\right)$, Brownian motion parameter $(\mathrm{Nb})$ and thermophoresis parameter $(\mathrm{Nt})$. The results are presented graphically in Figs. 2-8 and conclusions are drawn for flow field and other physical quantities of interest that have significant effects.

The volume fraction of nanoparticles is a key parameter for studying the effect of nanoparticles on flow fields and temperature distributions. Thus, Figs. 2-3 are prepared to present the effect of the Brownian motion and thermophoresis effect on the temperature distribution and the volume fraction of nanoparticles. Fig. 2 shows the temperature distributions in the thermal boundary layer for different values of the Brownian motion and the thermophoresis parameters. As both $N b$ and $N t$ increase, the boundary layer thickens, the surface temperature increases, and the curves become less steep indicating a diminution of the reduced Nusselt number. It is interesting to note that the Brownian motion of nanoparticles, at molecular and nanoscale levels, is a key nanoscale mechanism governing their thermal behaviors. In nanofluid systems, due to the size of the nanoparticles, the Brownian motion takes place, which can affect the heat transfer properties. As the particle size scale approaches to the nanometer scale, the particle Brownian motion and its effect on the surrounding liquids play an important role in the heat transfer.

While thermophoresis effect is important in natural convection of nanofluids, there are other parameters which may have effects and should be considered. These effects include the increase in effective viscosity of nanofluids due to the presence of nanoparticles and the density variation due to the variable volume fraction. Larger volume fraction of nanoparticles makes nanofluids more viscous and the mixture of convection becomes weaker, and thus decreases the natural convective Nusselt number due to high viscose fluid. On the other hand, it is showed that the separation factor for common nanofluids is positive and the density variation due to the variable volume fraction of nanoparticles, called particulate buoyancy force, helps nanofluids to have strong convection heat transfer.

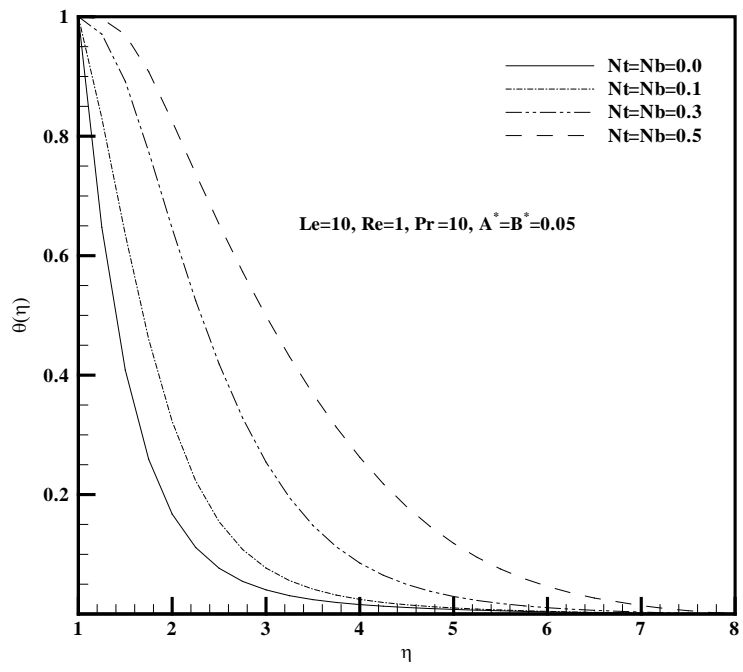

Fig. 2 Effect of $N_{t}$ and $N_{b}$ on temperature profiles.

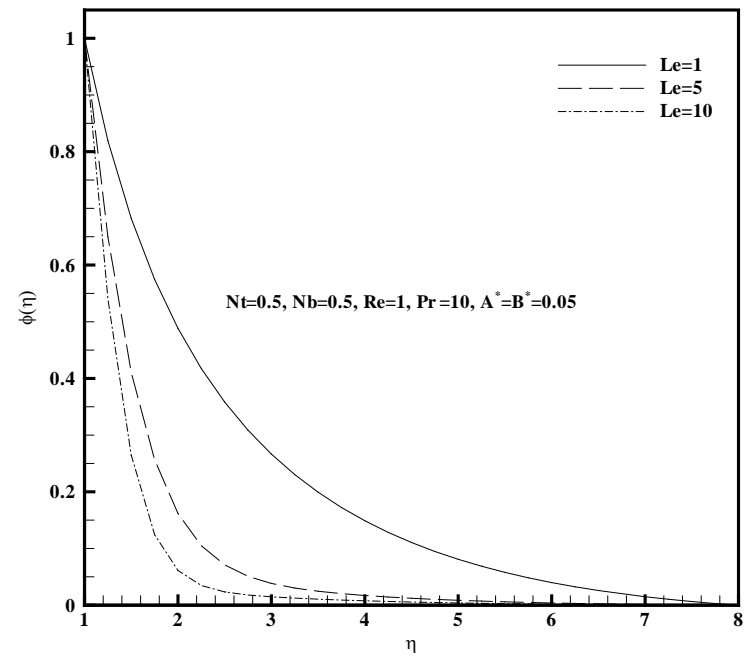

Fig. 3 Effect of Le on concentration profiles.

The variation of nanoparticle concentration (volume fraction) for various Lewis numbers is shown in Fig. 3. It can be seen that the Lewis number significantly affects the concentration distribution. For a base fluid of certain kinematic viscosity $v$, a higher Lewis number implies a lower Brownian diffusion coefficient $D_{B}$ which must result in a shorter penetration depth for the concentration boundary layer. In fact, this is exactly what we see in Fig. 3.

Table 3 Effect of nanofluid on the rate of heat transfer

$$
N_{t}=N_{b}=0 \quad N_{t}=N_{b}=0.1 \quad N_{t}=N_{b}=0.3 \quad N_{t}=N_{b}=0.5
$$

$\begin{array}{lllll}-\theta^{\prime}(1) & 0.39161 & 0.33289 & 0.23715 & 0.16475\end{array}$




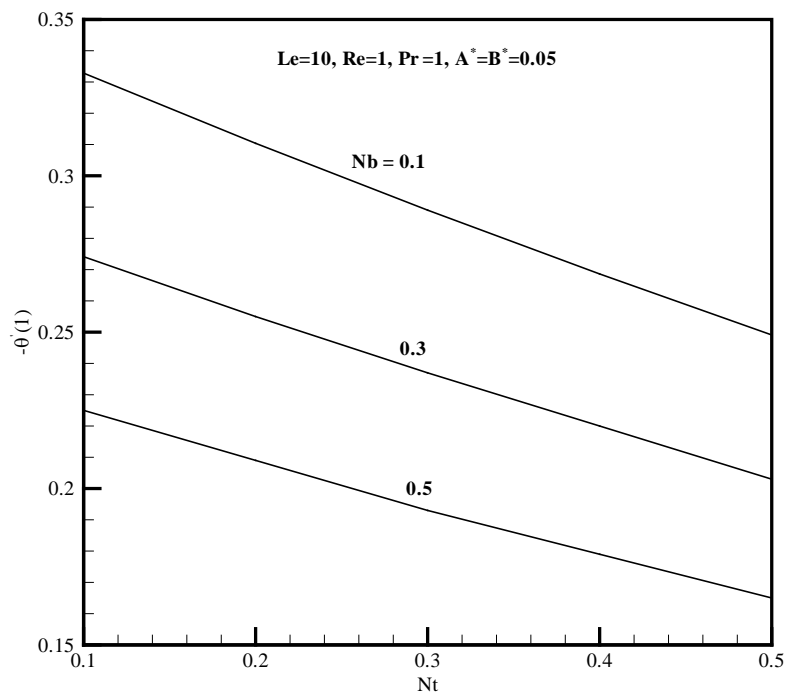

Fig. 4 Reduced local Nusselt number versus $N_{t}$ for various $N_{b}$.

The results of addition nanoparticles on heat transfer rate on the cylinder wall have been shown in the Table 3. It is found that nanofluid deteriorates the rate of heat transfer on the stretching cylinder surface. Fig. 4 indicates the effect of $N t$ and $N b$ on reduced Nusselt number. It seems that for fixed thermophoresis parameter $N t$, the reduced Nusselt number decreases sharply with the increase in Brownian motion, that as $\mathrm{Nb}$ is increased from 0.1 to 0.5 . As the Brownian motion intensifies, it impacts a larger extent of the fluid, causing the thermal boundary layer to thicken, which in turn decreases the reduced Nusselt number. On the other hand, the reduced Nusselt number decreases as the thermophoresis diffusion penetrates deeper into the fluid and causes the thermal boundary layer to thicken. These observations are consistent with the initial slopes of the temperature profiles, as discussed before.

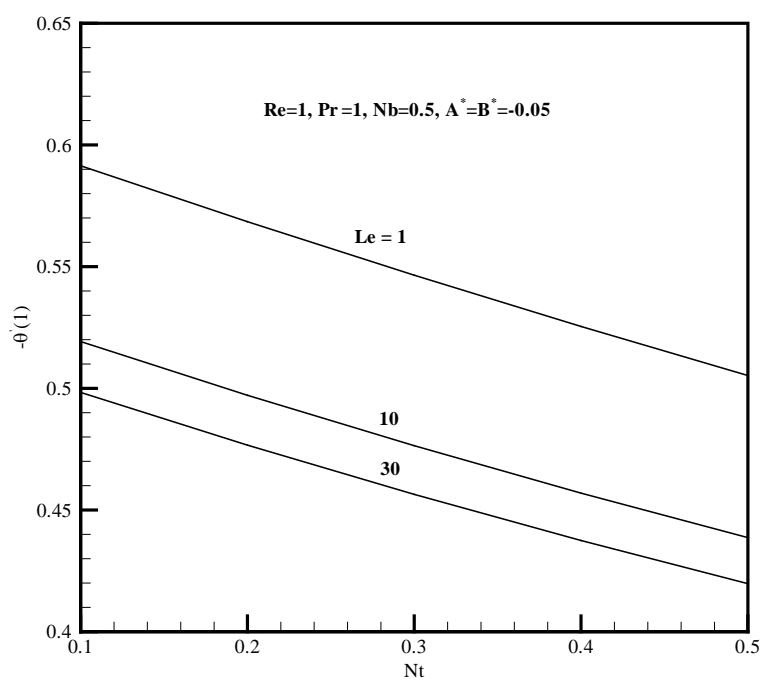

Fig. 5 Reduced local Nusselt number versus $N_{t}$ for various $L e$.

Figure 5 illustrates the effect of Lewis number on the reduced Nusselt number. It is found that when $\operatorname{Pr}, \operatorname{Re}, N b, A^{*}$ and $B^{*}$ fixed at 1 , $1,0.5,-0.05$ and -0.05 respectively, an increase in Lewis number causes the reduced Nusselt number to decrease. We notice that, the effect of increasing the thermophoretic parameter $\mathrm{Nt}$ is limited to increasing slightly the wall slope of the nanoparticle volume fraction profiles, but decreasing the nanoparticle volume fraction. This is true only for small Lewis numbers for which the Brownian diffusion effect is large compared with the convection effect. However, for large Lewis numbers, the diffusion effect is minimal compared with the convection effect. Therefore, the thermophoretic parameter $N t$ is expected to alter the nanoparticle volume fraction boundary layer significantly.

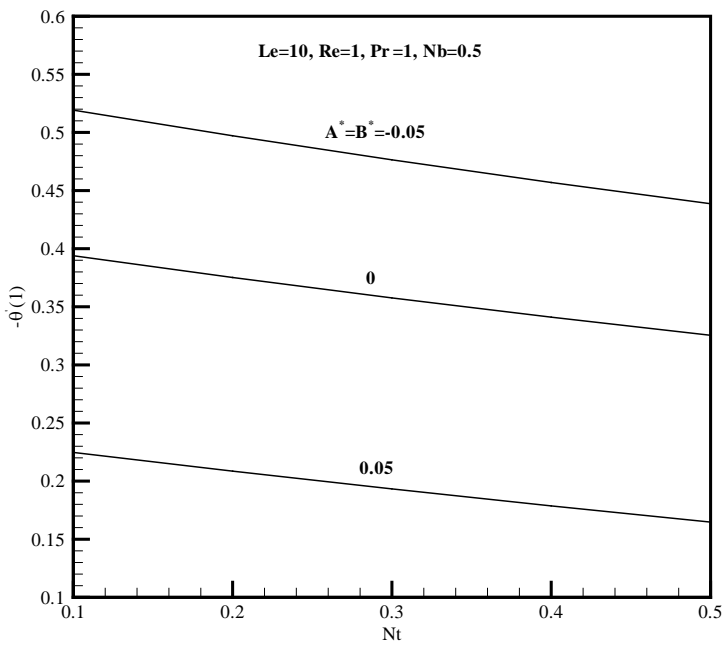

Fig. 6 Reduced local Nusselt number versus $N_{t}$ for various $A^{*}, B^{*}$.

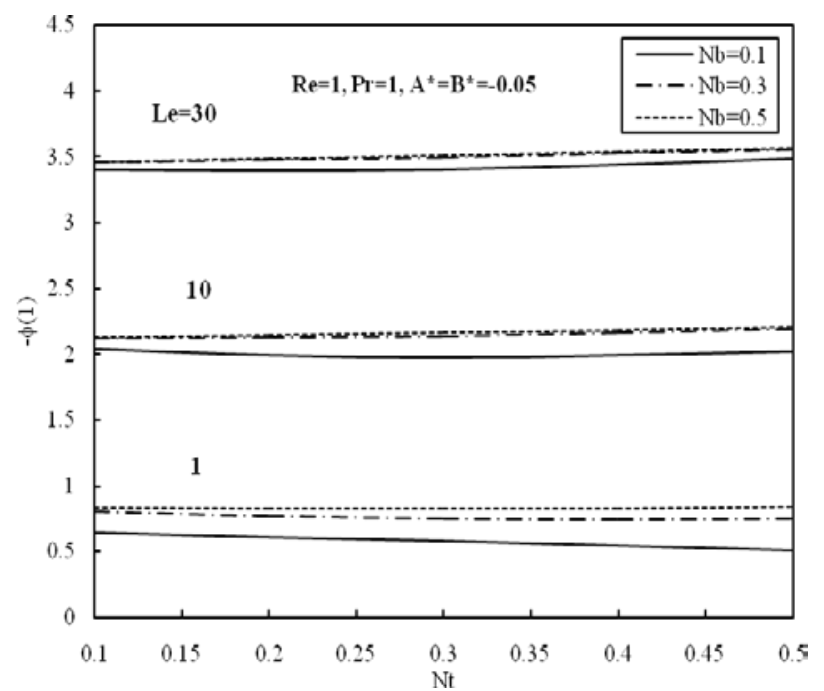

Fig. 7 Reduced local Sherwood number versus $N_{t}$ for various $L e$ and $N_{b}$.

The influence of non-uniform heat source/sink parameters on reduced Nusselt number has been shown in fig. 6. It is pointed out from this figure that increasing the values of space-dependent heat source/sink parameter $A^{*}$ and temperature dependent heat source/sink parameter $B^{*}$ leads to a fall in the value of reduced Nusselt number.

It can be seen from fig. 7 that mass transfer rates increase slightly with $\mathrm{Nb}$, while it remains almost constant with variation of $N t$. The mass transfer rate is also found to increase dramatically with increasing Lewis number. Fig. 8 describes the variation of mass transfer rate versus thermophoresis parameter $N t$ for different parameters namely Prandtl number and non-uniform heat source/sink parameters. It is anticipated that the change in Prandtl number from 1 to 10 results in considerable increase in the mass transfer rate. It is also seen that an increase in both the space-dependent heat source/sink parameter $A^{*}$ and temperature dependent heat source/sink parameter $B^{*}$ brings about augmentation of the Reduced local Sherwood number. However, this increase is more noticeable for lower Prandtl number. 


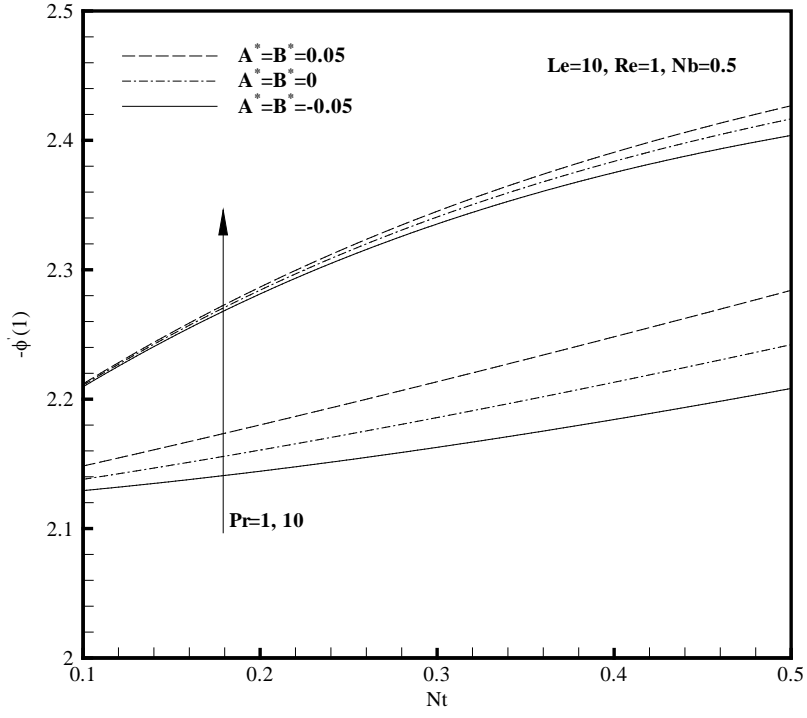

Fig. 8 Reduced local Sherwood number versus $N_{t}$ for various $\operatorname{Pr}$ and $A^{*}, B^{*}$.

\section{Conclusions}

A combined similarity-numerical approach was used to study the boundary layer flow in a nanofluid over a stretching cylinder in the presence of non-uniform heat source/sink. For the nanofluid, we employed a model that accounts for the mechanics of the nanoparticle/base fluid relative velocity by incorporating the effects of Brownian motion and thermophoresis into the governing equations. The influences of the significant parameters, namely Prandtl number $\mathrm{Pr}$, Lewis number $L e$, Brownian motion parameter $N b$, thermophoresis parameter $N t$ and non-uniform heat generation/absorption parameters $A^{*} \& B^{*}$, on the flow and heat transfer characteristics have been examined. The results reveal that the rate of heat transfer $-\theta^{\prime}(1)$ decreases as Brownian motion parameter and thermophoresis parameter go up, but there is an augmentation in heat transfer rate when the values of Lewis number and non-uniform heat generation/absorption parameters increase. Moreover, it was predicted that the reduced Sherwood number increases as the amount of $L e, A^{*}, B^{*}$ and $\mathrm{Pr}$ intensify. By contrast, the Brownian motion parameter deteriorates the rate of mass transfer over the stretching cylinder especially for small Lewis number. Ultimately, we can draw the conclusion that the nanofluid parameters display a considerable effect on the rates of heat and mass transfer over a stretching cylinder.

\section{NOMENCLATURE}

$A^{*} \quad$ space dependent heat source/sink

$B^{*} \quad$ temperature dependent heat source/sink

C concentration, $\left(\mathrm{kg} / \mathrm{m}^{3}\right)$

$C_{f} \quad$ local skin-friction coefficient

$D_{B} \quad$ Brownian diffusion coefficient, $(\mathrm{kg} / \mathrm{m} . \mathrm{s})$

$D_{T} \quad$ thermophoretic diffusion coefficient, (kg/m.s.K)

$f \quad$ similarity function for stream function

$g$ gravitational acceleration, $\left(\mathrm{m} / \mathrm{s}^{2}\right)$

$k \quad$ thermal conductivity, (W/m.K)

Le Lewis number

$N_{b} \quad$ Brownian motion parameters

$N_{t} \quad$ thermophoresis parameters

$\mathrm{Nu} \quad$ Nusselt number

p pressure, $\left(\mathrm{N} / \mathrm{m}^{2}\right)$

$\mathrm{Pr} \quad$ Prandtl number

$q \quad$ wall heat flux, $\left(\mathrm{W} / \mathrm{m}^{2}\right)$

$\begin{array}{ll}R e & \text { Reynolds number } \\ S & \text { shear stress, }\left(\mathrm{N} / \mathrm{m}^{2}\right) \\ S h_{x} & \text { local Sherwood number } \\ T & \text { temperature, }(\mathrm{K}) \\ u, w & \text { velocity components along } \mathrm{r} \text { and } \mathrm{z} \text { direction, }(\mathrm{m} / \mathrm{s})\end{array}$

Greek symbols

$\alpha \quad$ thermal diffusivity, $\left(\mathrm{m}^{2} / \mathrm{s}\right)$

$\eta \quad$ dimensionless distance

$\theta \quad$ dimensionless temperature

$v \quad$ Kinematic viscosity

$\rho \quad$ density

$(\rho c) \quad$ effective heat capacity, $\left(\mathrm{kg} / \mathrm{m}^{3} \cdot \mathrm{K}\right)$

$\tau \quad$ ratio between the effective heat capacity of the nanoparticle material and heat capacity of the fluid

$\begin{array}{ll}\text { Subscripts } & \\ f & \text { fluid } \\ p & \text { nanoparticle } \\ \infty & \text { ambient } \\ \mathrm{w} & \text { wall }\end{array}$

\section{REFERENCES}

Altan, T., Oh, S., Gegel, H. 1979, Metal Forming Fundamentals and Applications, $1^{\text {st }}$ ed., American Society of Metals, Metals Park, OH.

Anbuchezhian, N., Srinivasan, K., Chandrasekaran, K., Kandasamy, R., 2012, "Thermophoresis and Brownian Motion Effects on Boundary Layer Flow of Nanofluid in Presence of Thermal Stratification due to Solar Energy,” Appl. Math. Mech, 33(6), 765-780. http://dx.doi.org/Doi:10.1007/s10483-012-1585-8.

Aziz, A., Khan, W.A., 2012, "Natural Convective Boundary Layer Flow of a Nanofluid Past a Convectively Heated Vertical Plate," International Journal of Thermal Sciences, 52, 83-90.

http://dx.doi.org/10.1016/j.ijthermalsci.2011.10.001.

Buongiorno, J., 2006, “Convective Transport in Nanofluids," ASME J. Heat Transfer, 128, 240-250.

http://dx.doi.org/10.1115/1.2150834.

Chamkha, A.J., Abd El-Aziz, M.M., Ahmed, S.E., 2010, "Effects of Thermal Stratification on Flow and Heat Transfer due to a Stretching Cylinder with Uniform Suction/Injection," International Journal of Energy and Technology, 2, 1-7.

Choi, S.U.S., 1995, "Enhancing Thermal Conductivity of Fluids with Nanoparticles," Developments and Applications of Non-Newtonian Flows, 66, 99-105.

Dandapat, B.S., Santra, B., Vajravelu, K., 2007, “The Effects of Variable Fluid Properties and Thermocapillarity on the Flow of a Thin Film on an Unsteady Stretching Sheet," Int J Heat Mass Transf, 50, 991-996.

http://dx.doi.org/10.1016/j.ijheatmasstransfer.2006.08.007.

Eastman, J.A., Phillpot, S.R., Choi, S.U.S., Keblinski, P., “Thermal Transport in nNanofluids," Annu. Rev. Mater. Res, 34, 219-246. http://dx.doi.org/10.1146/annurev.matsci.34.052803.090621.

Fan, J., Wang, L., 2011, "Heat Conduction in Nanofluids: StructureProperty Correlation,” Int J Heat Mass Transf, 54, 49-4359. http://dx.doi.org/10.1016/j.ijheatmasstransfer.2011.05.009.

Gorla, R., El-Kabeir, S.M.M., Rashad, A.M., 2011, "Boundary-Layer Heat Transfer from a Stretching Circular Cylinder in a Nanofluid," Journal of thermophysics and heat transfer, 25, 183-185. http://dx.doi.org/doi:10.2514/1.51615. 
Hassani, M., Mohammad Tabar, M., Nemati, H., Domairry, G., Noori, F., 2011, "An Analytical Solution for Boundary Layer Flow of a Nanofluid Past a Stretching Sheet," International Journal of Thermal Sciences, 50, 2256-2263. http://dx.doi.org/10.1016/j.ijthermalsci.2011.05.015.

Ishak, A., Nazar, R., Pop, I., 2008, "Uniform Suction/Blowing Effect on Flow and Heat Transfer due to a Stretching Cylinder," Applied Mathematical Modelling, 32, 2059-2066. http://dx.doi.org/10.1016/j.apm.2007.06.036.

Joneidi, A.A., Domairry, G., Babaelahi, M., Mozaffari, M., 2010, "Analytical Treatment on Magnetohydrodynamic (MHD) Flow and Heat Transfer due to a Stretching Hollow Cylinder,” Int. J. Numer. Meth. Fluids, 63, 548-563.

http://dx.doi.org/doi:10.1002/fld.2087.

Kakac, S., Pramuanjaroenkij, A., 2009, "Review of Convective Heat Transfer Enhancement with Nanofluids,” Int. J. Heat Mass Transfer, 52, 3187-3196.

http://dx.doi.org/10.1016/j.ijheatmasstransfer.2009.02.006.

Khan, S.K., Subhas Abel, M., Sonth Ravi, M., 2003, "Viscoelastic MHD Flow, Heat and Mass Transfer Over a Porous Stretching Sheet with Dissipation of Energy and Stress Work," Int J Heat Mass Transf, 40, 47-57.

http://dx.doi.org/10.1007/s00231-003-0428-x

Khan, W.A., Pop, I., 2010, "Boundary-Layer Flow of a Nanofluid Past a Stretching Sheet,” Int. J. Heat Mass Transf, 53, 2477-2483. http://dx.doi.org/10.1016/j.ijheatmasstransfer.2010.01.032.

Kuznetsov, A.V., Nield, D.A., 2010, "Natural Convective Boundary Layer Flow of a Nanofluid Past a Vertical Plate,” International Journal of Thermal Sciences, 49(2), 243-247.

http://dx.doi.org/10.1016/j.ijthermalsci.2009.07.015.

Liu, I.C., 2004, "Flow and Heat Transfer of an Electrically Conducting Fluid of Second Grade Over A Stretching Sheet Subject to a Transverse Magnetic Field," Int J Heat Mass Transf, 47, 4427-4437. http://dx.doi.org/10.1016/j.ijheatmasstransfer.2004.03.029.

Mahantesh, M., Nandeppanavar, K., Vajravelu, M., Subhas, M., ChiuOn, N.g., 2011, "Heat Transfer over a Nonlinearly Stretching Sheet with Non-Uniform Heat Source and Variable Wall Temperature," Int J Heat Mass Transf, 54, 4960-4965.

http://dx.doi.org/10.1016/j.ijheatmasstransfer.2011.07.009.
Makinde, O.D., Aziz, A., 2011, "Boundary Layer Flow of a Nanofluid Past a Stretching Sheet with a Convective Boundary Condition," International Journal of Thermal Sciences, 50, 1326-1332. http://dx.doi.org/10.1016/j.ijthermalsci.2011.02.019.

Nadeem, S., Hussain, A., Khan, M., 2010, “HAM Solutions For Boundary Layer Flow In The Region Of The Stagnation Point Towards A Stretching Sheet,” Comm Nonlinear Sci Numer Simul, 15, 475-481. http://dx.doi.org/10.1016/j.cnsns.2009.04.037

Nadeem, S., Lee, C., 2012, "Boundary Layer Flow of Nanofluid over an Exponentially Stretching Surface,” Nanoscale Research Letters, 7, 94.

http://dx.doi.org/doi:10.1186/1556-276X-7-94.

Nandeppanavar, M., Subhas Abel, M., Tawade, J., 2010, “Heat Transfer in a Walter's Liquid B Fluid over an Impermeable Stretching Sheet with Non-uniform Heat Source/sink and Elastic Deformation,” Commun Nonlinear Sci Numer Simulat, 15, 1791-1802. http://dx.doi.org/10.1016/j.cnsns.2009.07.009.

Pal, D., Mondal, H., 2012, "Soret and Dufour Effects on MHD NonDarcian Mixed Convection Heat and Mass Transfer over a Stretching Sheet with Non-uniform Heat Source/sink,” Physica B, 407,642-665. http://dx.doi.org/10.1016/j.physb.2011.11.051.

Prasad, K.V., Subhas Abel, M., Ambuja, J., 2000, “Oscillatory Motion of a Visco-elastic Fluid over a Stretching Sheet in Porous Media," $J$. Porous Media, 3(1), 61.

Sakiadis, B.C., 1971, "Boundary Layer Behavior on Continuous Solid Surfaces: I Boundary Layer Equations for Two Dimensional and Axisymmetric Flow," AIChE 61, 26-34. http://dx.doi.org/10.1002/aic.690070108.

Tidmore, Z., Klein, I., 1970, Engineering Principles of Plasticating Extrusion, $2^{\text {nd }}$ ed., Polymer Science and Engineering Series, Van Norstrand, New York.

Trisaksri, V., Wongwises, S., 2007, "Critical Review of Heat Transfer Characteristics of Nanofluids,” Renew. Sust. Energ. Rev, 11,512-523. http://dx.doi.org/10.1016/j.rser.2005.01.010.

Wang, C.Y., 1988, "Fluid Flow due to a Stretching Cylinder," Physics of Fluids, 31,466-468. http://link.aip.org/link/doi/10.1063/1.866827.

Wang, X.Q., Mujumdar, A.S., 2007, "Heat Transfer Characteristics of Nanofluids: a review,” Int. J. Therm. Sci, 46, 1-19. http://dx.doi.org/10.1016/j.ijthermalsci.2006.06.010. 